\title{
Cost-Effectiveness Analysis of Metronidazole versus Metronidazole with Diloxanide Furoate in the Treatment of Amoebiasis in Ethiopia
}

\author{
Nanati Legese' \\ Temesgen Aferu (iD) ${ }^{2}$ \\ Tsehay Kassa ${ }^{3}$ \\ 'School of Pharmacy, College of Health \\ and Medical Sciences, Haramaya \\ University, Harar, Ethiopia; ${ }^{2}$ School of \\ Pharmacy, College of Medicine and \\ Health Sciences, Mizan Tepi University, \\ Mizan Aman, Ethiopia; ${ }^{3}$ Teklehaimanot \\ health center, Addis Ababa, Ethiopia
}

Introduction: Amoebiasis is one of the world's most prevalent and fatal infectious diseases. Several surveys revealed that amoebiasis is one of the most widely distributed diseases in Ethiopia. The combination of metronidazole with diloxanide furoate represents a new approach for the treatment of the infection.

Objective: This study aimed to analyze the cost-effectiveness of diloxanide plus metronidazole compared with metronidazole alone in the treatment of amoebiasis in Ethiopia.

Methods: An analytical decision model was used to analyze costs and effectiveness from a societal perspective by taking adult amoebic patients as the study population with a time horizon of two months. The potential impacts of uncertainty in single parameters were explored in one-way sensitivity analyses.

Results: Metronidazole with diloxanide had a higher cost and effect compared to metronidazole alone with an incremental cost-effectiveness ratio (ICER) of 8 US\$ per amoebic case cured. The result was sensitive to the decrease in the effectiveness of metronidazole with diloxanide.

Conclusion: This study revealed the addition of diloxanide to standard treatment to be a more effective and more costly treatment strategy. Therefore, a decision for choosing the medication should be based on the ability of patients to pay for the treatment.

Keywords: amoebiasis, metronidazole, metronidazole with diloxanide, cost-effectiveness analysis, Ethiopia

\section{Introduction}

Amoebiasis is the third leading parasitic cause of mortality after malaria and schistosomiasis. ${ }^{1}$ Annually, around 500 million peoples are infected worldwide while 40 to 100,000 (75,000 on average) die of the disease. ${ }^{1-3}$ Eighty to ninety percent of those infected are asymptomatic and one percent may develop invasive/extra-intestinal amoebiasis. ${ }^{2,3}$

Studies in Ethiopia indicated that amoebiasis is one of the most widely distributed diseases. ${ }^{4}$ In a countrywide survey of 97 communities, the overall prevalence of amoebiasis, as measured by the rate of cyst-passers, in non-school communities was $3.5 \%{ }^{5}$ In another study in 50 communities in Northern Ethiopia, the prevalence of amebiasis ranged a 3\% to 55\%. Management of the infection caused a significant economic burden in this area and other parts of the country where the disease was widespread. ${ }^{6}$

Although frequently overlooked in practice, for the adequate therapy of invasive amoebiasis, treatment should be directed at all the sites where the parasite is 
present. Luminal or contact amoebicides will not be effective against amoebae in the tissues. On the other hand, parenteral amoebicides do not possess sufficient activity against amoebae in the bowel lumen. ${ }^{7}$

Metronidazole is sufficient for the treatment of hepatic amoebiasis resulting in an apparent cure. However, the dose may be inadequate in amoebic dysentery and patients are liable to a symptomless cyst-passing state with the danger of subsequent relapse. The drug is highly absorbed and is more active in the tissues than in the gut lumen. It follows that a higher dose is needed to cure luminal than systemic infections. Besides, most strains of Escherichia coli are capable of inactivating metronidazole. The drug is also characterized by a short duration of action, repeat dosage requirement, and possible drug resistance. ${ }^{7,8}$ As a result, drugs with a longer half-life and more convenient dosage regimen and combinations with other active drugs are needed to meet these demands. Diloxanide furoate is a luminal, while metronidazole is both luminal and tissue amoebicide. The combination of the two medications represents a new approach for the treatment of the infection. ${ }^{9}$ Contrary to this, the standard treatment guideline in Ethiopia recommends metronidazole $750 \mathrm{mg}$ three times a day for seven days as the first-line treatment. ${ }^{10}$

Even though researches suggested the clinical significance of the combination of metronidazole with diloxanide over metronidazole alone, the economic side of this treatment strategy remains uncertain. Therefore, this study analyzed the incremental costs, effects, and costeffectiveness of these treatment options. The analysis was from a societal perspective by taking adult amoebic groups as a study population.

\section{Method}

\section{Description of the Intervention}

Eradicating the parasite is the essential outcome measure to prevent the risk of relapse and recurrences from amoebiasis. ${ }^{8}$ Therefore, case cured (parasite eradicated) was a primary efficacy measure used in this economic analysis.

The two alternative treatment protocols analyzed were:

1. Metronidazole alone

2. Metronidazole with diloxanide furoate

Both metronidazole and diloxanide is a prescription drug that is available in an oral dosage.
The required dose in the first alternative is metronidazole $800 \mathrm{mg}$ three times a day for seven days. ${ }^{8}$ For patients not cured with metronidazole, diloxanide furoate $500 \mathrm{mg}$ three times a day for ten days is the subsequent therapy. ${ }^{3}$ In the second alternative, metronidazole $400 \mathrm{mg}$ and diloxanide furoate $500 \mathrm{mg}$ three times a day for five days is recommended. ${ }^{11}$

PubMed and Google Scholar were the searched database for finding evidence. Besides, the pharmaceutical fund and supply agency (state-owned importer and distributor of pharmaceuticals in Ethiopia), the ministry of health and expert opinions were incorporated.

We found one randomized controlled trial that compared metronidazole and diloxanide over metronidazole alone. ${ }^{11}$ We also found a meta-analysis of 9 randomized controlled trials on the effectiveness of metronidazole. ${ }^{12}$ All the results of effectiveness data were based on probabilities.

We constructed a decision tree to calculate the expected costs and effectiveness of alternative therapies. Discounting of costs and effects was not necessary since the time horizon of the study was only two months. We chose this time horizon because relapse from amoebiasis most frequently occurs within 4 to 6 weeks of completing treatment. ${ }^{8}$

We analyzed direct costs and effects from the societal perspective and calculated incremental costs, effects, and cost-effectiveness for both treatment strategies. We presented all monetary values in the 2016 US dollar (US\$) with an average exchange rate of 21.4 Ethiopian Birr per US\$.

\section{Calculating Effectiveness}

We calculated the expected clinical outcomes for the two alternative strategies using a decision tree model (Figure 1). Amoebic patients may either take metronidazole alone or metronidazole with diloxanide furoate. Both of these alternatives have a probability of cure or not. Amoebic patients not cured with metronidazole alone are assumed to return to the health facility to take diloxanide furoate, which again has the probability of cure or not.

For the first alternative (metronidazole alone), the likelihood of a favorable treatment outcome (cure) was based on evidence from a systematic review and meta-analysis of nine randomized clinical trials conducted on populations with both suspected and documented disease in endemic areas. ${ }^{12}$ And the probability of cure of diloxanide was found from one randomized clinical trial. ${ }^{18}$ The cure rate for patients who took metronidazole alone was $86 \%{ }^{12}$ And of those who 


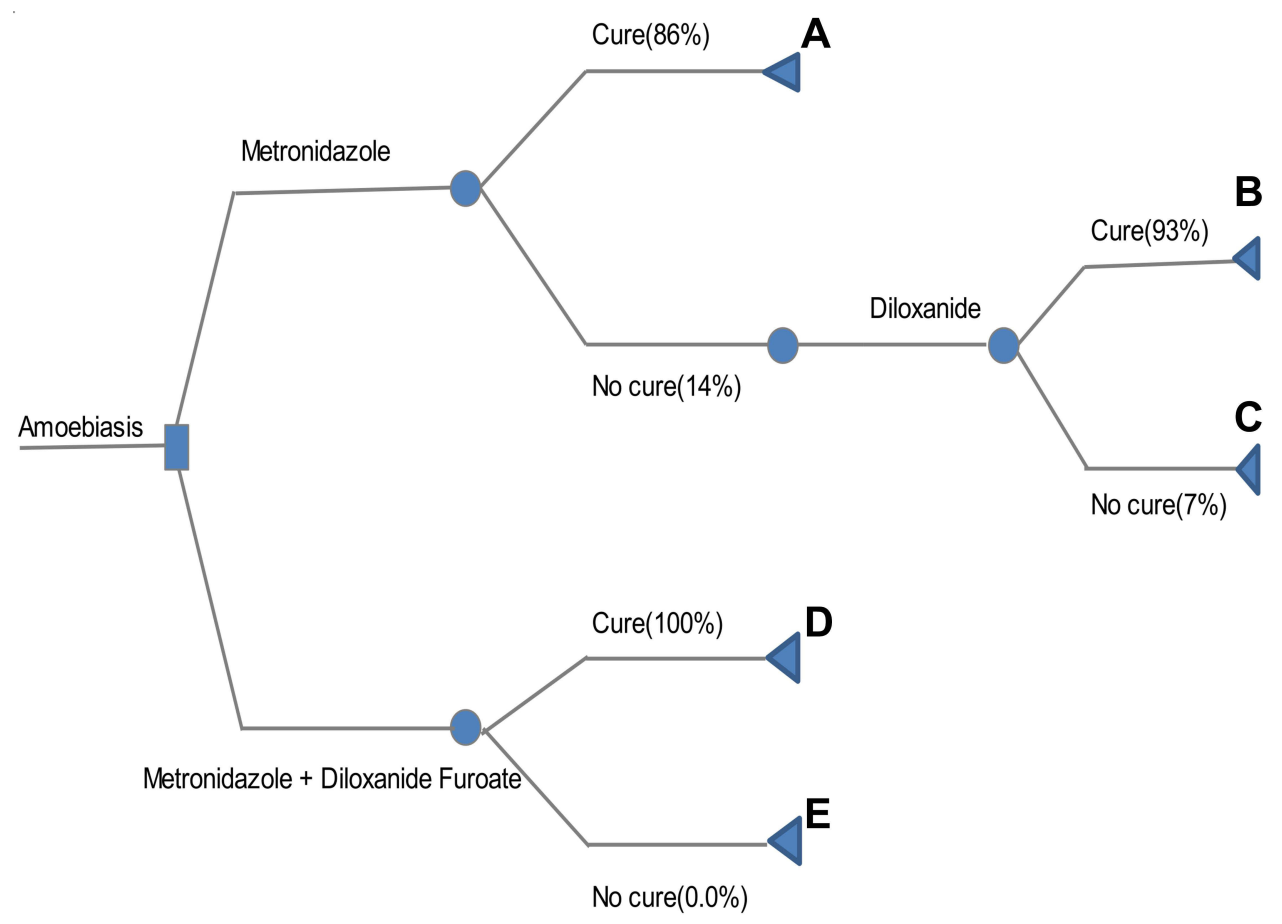

Figure I Analytical decision model.

failed, $93 \%$ were cured with the diloxanide given on their second visit. ${ }^{18}$

For the second alternative, the effectiveness data was found from one randomized controlled trial that compared metronidazole against metronidazole with diloxanide furoate. In the study, all amoebic patients treated with metronidazole combined with diloxanide get cured $(100 \%) .{ }^{11}$ (Table 1)

\section{Mortality from Amoebiasis}

Mortality from amoebiasis is highly associated with the complications of the disease. Severe toxemia, perforation of the bowel, toxic megacolon, rupture of the hepatic abscess into pleura, lung, peritoneum, pericardium, skin, and subcutaneous tissue are among the complications leading to death. Hepatic abscess-producing obstructive jaundice can also occur. Fever, leukocytosis with elevated polymorphs, rise in hepatic enzymes and serum bilirubin are the accompaniments of the complications. Late diagnosis and treatment increase the probability of complications and mortality from amoebiasis. The global mortality rate of amoebiasis is $36,040,000(7.5 \%)$ per 480 million people infected, the majority of the death being secondary to complications. This complication and death usually occur due to delay in starting therapy or treatment failure. ${ }^{13}$ Based on this, we assumed that $7 \%$ of the individuals in the first alternative would face treatment failure, a complication from the disease, or death.

\section{Calculating Costs}

The cost items incorporated were: health professional consultation time costs, laboratory examination costs,

Table I Effectiveness of Metronidazole Alone versus Metronidazole with Diloxanide Furoate

\begin{tabular}{|c|c|c|c|c|}
\hline & & \multicolumn{2}{|l|}{ Alternative I } & \multirow{2}{*}{$\begin{array}{l}\text { Alternative } 2 \text { (Metronidazole with } \\
\text { Diloxanide) }\end{array}$} \\
\hline & & $\begin{array}{l}\text { Metronidazole } \\
\text { Alone }\end{array}$ & $\begin{array}{l}\text { Diloxanide After the Failure of } \\
\text { Metronidazole }\end{array}$ & \\
\hline Outcome & $\begin{array}{l}\text { Cured } \\
\text { Not } \\
\text { cured }\end{array}$ & $\begin{array}{l}86 \%^{12} \\
14 \%\end{array}$ & $\begin{array}{l}93 \%{ }^{18} \\
7 \%\end{array}$ & $\begin{array}{l}100 \%^{11} \\
0 \%\end{array}$ \\
\hline
\end{tabular}


Table 2 Costs Parameters (US \$)

\begin{tabular}{|c|c|c|c|c|c|}
\hline & \multirow[b]{3}{*}{$\begin{array}{c}\text { Cost per Tablet/per } \\
\text { Capsule }\end{array}$} & \multicolumn{4}{|c|}{ Medication Costs } \\
\hline & & \multicolumn{2}{|l|}{ Alternative I } & \multicolumn{2}{|c|}{ Alternative 2} \\
\hline & & $\begin{array}{c}\text { Duration of Treatment in } \\
\text { Days }\end{array}$ & $\begin{array}{c}\text { Cost per } \\
\text { Case } \\
\text { Treated }\end{array}$ & 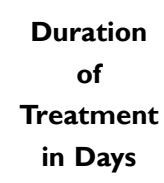 & $\begin{array}{c}\text { Cost per Case } \\
\text { Treated }\end{array}$ \\
\hline Metronidazole & 0.02 & 7 & 1.24 & 5 & 0.59 \\
\hline \multirow[t]{4}{*}{ Diloxanide } & \multirow[t]{4}{*}{0.12} & 10 & 3.77 & 5 & 1.89 \\
\hline & & \multicolumn{4}{|c|}{ Other Costs } \\
\hline & & \multicolumn{3}{|c|}{ Alternative I } & Alternative 2 \\
\hline & & Cured with Metronidazole & \multicolumn{2}{|c|}{$\begin{array}{l}\text { Not Cured } \\
\text { with } \\
\text { Metronidazole }\end{array}$} & \\
\hline Physician visit & $3.04^{\mathrm{a}}$ & 3.04 & \multicolumn{2}{|c|}{6.08} & 3.04 \\
\hline Laboratory examination & $1.07^{\mathrm{b}}$ & 1.07 & \multicolumn{2}{|c|}{2.14} & 1.07 \\
\hline $\begin{array}{l}\text { Health care providers } \\
\text { salary }\end{array}$ & 0.074 & 0.074 & \multicolumn{2}{|c|}{0.15} & 0.074 \\
\hline Transportation & $0.36^{\mathrm{c}}$ & 0.36 & \multicolumn{2}{|c|}{0.72} & 0.36 \\
\hline
\end{tabular}

Notes: a Cost per visit; ${ }^{b}$ Cost per examination; ${ }^{c}$ Cost per trip.

medication cost, physician visits cost, medical supplies cost, and transportation costs. Most of these costs are the same for both alternatives. However, medication costs, laboratory examination costs, physician visits costs, health professional consultation time costs, and transportation costs are doubled for patients not cured with metronidazole alone (alternative 1).

We found the cost of metronidazole from the market prices of 10 public and private pharmacies in different areas of Addis Ababa. Because the cost distribution is skewed, we took the mean cost $(0.02 \$$ per capsule). Therefore, the total cost of metronidazole needed in the first alternative was $1.24 \$$. Also, we found the cost of diloxanide furoate from 10 community pharmacies in Addis Ababa (the medication was not available in public facilities), and we used the mean cost $(0.12 \$$ per tablet).

We obtained laboratory examination costs from 10 private facilities in Addis Ababa (laboratory examination cost is subsidized in public facilities), and we used the mean cost (1.07\$ per one examination). The physician visit cost (3.04\$) was also the mean cost obtained from 10 private health facilities (physician visit cost is subsidized in public facilities).
In Ethiopia, amoebic patients are usually treated in health centers by health officers or nurses whose salary was $147 \$$ per month, and the national average consultation time at the outpatient department was 10 minutes (from the expert opinion). Therefore, the cost for 10 minutes of consultation time was 0.03 US\$. Also, the average stool examination time was 10 minutes (from the expert opinion) and, since the salary of the laboratory technician was the same as that of the health officer, the cost for 10 minutes examination time was 0.03 US\$. We used the national average dispensing time (1.31 minutes) for calculating dispensing time cost. ${ }^{17}$ By taking the monthly salary of the dispenser (182.75US\$), the cost of dispensing time was 0.006 US\$. Finally, we used the national average transportation cost $\left(0.364 \$\right.$ per trip). ${ }^{14}$

Metronidazole costs 1.24 US\$ alone while it costs 0.59US\$ when given together with diloxanide. Diloxanide costs 3.77 US\$ on the failure of metronidazole alone, while it costs 1.89 US\$ together with metronidazole. Alternative two has a lower cost associated with physician visits, laboratory, health care providers, and transportation because all patients get cured on their first visit to the health facility (Table 2). 


\section{Uncertainty and Sensitivity Analysis}

There is uncertainty on the rate of effectiveness of diloxanide furoate (93\%) for patients not cured with metronidazole alone. We found the data from the study conducted on homosexual men. ${ }^{18}$ However, studies reported the number of parasites on homosexual men is higher than the general population. ${ }^{3,15}$ Also, there is uncertainty on the rate of effectiveness of metronidazole plus diloxanide (100\%). The study did not incorporate the confidence interval for the result. ${ }^{11}$ The other uncertainty was attached to the prices of medications. In the first alternative, the dose of metronidazole needed to treat amoebiasis is $800 \mathrm{mg}$ three times a day. However, the metronidazole dose available in the country is $250 \mathrm{mg} .{ }^{9}$ Hence, we used $750 \mathrm{mg}$ (3 capsules) of metronidazole to calculate the cost. Also, we took the price of $500 \mathrm{mg}$ ( 2 capsules of $250 \mathrm{mg}$ ) metronidazole instead of $400 \mathrm{mg}$ in the second alternative. On the other hand, we found the price of diloxanide from private pharmacies only. We determined the impacts of these uncertainties in one-way sensitivity analyses. We varied the costs of the medications by $20 \%$ and the effectiveness of metronidazole and diloxanide by $14 \%$ and $7 \%$ respectively, for the sensitivity analysis input not to exceed $100 \%$. We varied the effectiveness of metronidazole with diloxanide in one direction only because its effectiveness was $100 \%$.

\section{Results}

\section{Base Case Analysis}

The expected cost and effect of alternative 1 (metronidazole alone) were 6.94 US\$ and 0.99 , respectively. On the other hand, the expected cost and effect of alternative 2 (metronidazole with diloxanide) were 7.02 US\$ and 1, respectively. The incremental cost and effectiveness of metronidazole with diloxanide over metronidazole alone were 0.08 US $\$$ and 0.01 , respectively. The incremental cost-effectiveness ratio (ICER) was 8 US\$ per amoebiasis case cured (Table 3, Figure 2).

\section{Sensitivity Analysis}

In the one-way sensitivity analysis, the ICER was sensitive when the effectiveness of metronidazole with diloxanide varies to the lowest range. Metronidazole alone gives an extra expected effect of $0.19(0.99-0.8)$ at the same expected cost of 7.02 US\$. Therefore, metronidazole alone dominated the combination of metronidazole with diloxanide (Table 4).

\section{Discussion}

Based on this analysis, metronidazole with diloxanide was more effective and more costly with an ICER of 8 US \$ per case cured. However, we did not explore if metronidazole with diloxanide is affordable by society. How much of this incremental cost is paid varies with different coverage criteria and reimbursement policies of each plan. The sensitivity analysis revealed the same when the price of the medications varies. However, the result changed when we reduce the effectiveness of metronidazole with diloxanide. We ignored the tolerability difference between the two alternatives in the calculations made. Because metronidazole is common to both alternatives, there are no incremental cost differences due to adverse effects. Besides, studies revealed that diloxanide is a tolerable medication when given alone or in combination with metronidazole. ${ }^{3,8,11,16}$

Table 3 Outcome Values of the Decision Tree

\begin{tabular}{|c|c|c|c|c|c|c|c|c|}
\hline Outcome & Probability & Cost & $\begin{array}{c}\text { Expected } \\
\text { Cost }\end{array}$ & Effectiveness & $\begin{array}{c}\text { Expected } \\
\text { Effectiveness }\end{array}$ & $\begin{array}{c}\text { Incremental } \\
\text { Cost }\end{array}$ & $\begin{array}{c}\text { Incremental } \\
\text { Effect }\end{array}$ & ICER \\
\hline \multicolumn{6}{|l|}{ Alternative I } & \multirow[t]{9}{*}{0.08} & \multirow[t]{9}{*}{0.01} & \multirow[t]{9}{*}{8} \\
\hline A & 0.86 & 5.78 & 4.97 & I & 0.86 & & & \\
\hline B & 0.13 & 14.09 & 1.83 & I & 0.13 & & & \\
\hline C & 0.01 & 14.09 & 0.14 & 0 & 0 & & & \\
\hline Total & I & 33.96 & 6.94 & & 0.99 & & & \\
\hline \multicolumn{6}{|c|}{ Alternative II } & & & \\
\hline D & I & 7.02 & 7.02 & I & 1 & & & \\
\hline$E$ & 0 & 7.02 & 0 & 0 & 0 & & & \\
\hline Total & I & |4.04 & 7.02 & & 1 & & & \\
\hline
\end{tabular}

Notes: The outcomes (A, B, C, D, E) are shown in Figure I; Effectiveness, I is positive effect (amoebiasis cured); Effectiveness, 0 is negative effect (amoebiasis not cured). 


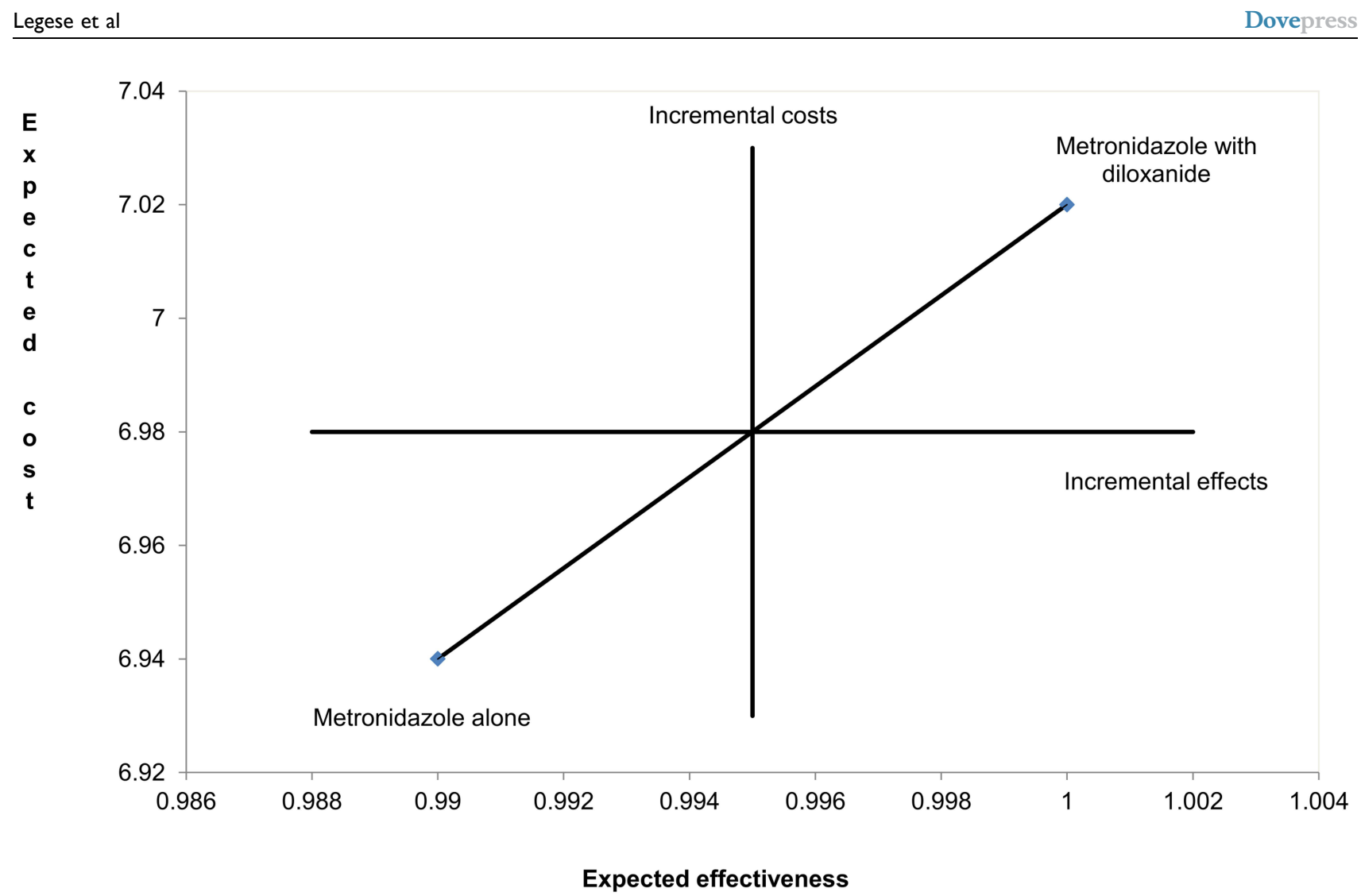

Figure 2 A cost effectiveness plane comparing metronidazole alone with metronidazole plus diloxanide.

\section{Limitation}

This study did not incorporate the indirect costs. Besides, the results are not generalizable to children and pregnant women.

\section{Conclusion}

A transition to metronidazole with diloxanide is associated with higher expected costs and effectiveness. The poorer sections of the community may face problems in paying for the treatment. Therefore, the current preference for metronidazole alone over the combination may continue

Table 4 Results from One Way Sensitivity Analysis

\begin{tabular}{|l|l|l|l|l|}
\hline \multirow{2}{*}{ Input Variable } & \multicolumn{2}{l|}{ Input Value } & \multicolumn{2}{l|}{ ICER } \\
\cline { 2 - 5 } & Low & High & Low & High \\
\hline Base line 8 & 0016 & 0.024 & 7 & -4.6 \\
\hline Metronidazole cost per capsule & 0096 & 0.144 & -25 & 27 \\
Diloxanide cost per tablet & 72 & 100 & 6 & NA \\
Metronidazole effectiveness & 86 & 100 & 4 & NA \\
Diloxanide effectiveness & 80 & NA & -0.42 & NA \\
Diloxanide with metronidazole \\
effectiveness & & & & \\
\hline
\end{tabular}

Abbreviation: NA, not applicable. unless the country shifts some of its resources based on its specific health care needs and financial capacity.

\section{Data Sharing Statement}

The datasets used and analyzed during the current study are available from the corresponding author upon reasonable request.

\section{Acknowledgments}

The authors would like to thank experts from the Ethiopian Federal Ministry of Health and Pharmaceuticals Fund and Supply Agency. Community pharmacies and private health facilities in Addis Ababa are also highly acknowledged for their contribution to this work.

\section{Disclosure}

The authors declare that they have no competing interests concerning the publication of this article.

\section{References}

1. Marie C, Verkerke HP, Theodorescu D, Petri WA. A whole-genome RNA screen uncovers a novel role for human potassium channels in cell killing by the parasite Entamoeba histolytica. Sci Rep. 2015;5:13613. doi:10.1038/srep13613 
2. Ximénez C, Morán P, Rojas L, Valadez A, Gómez A. Reassessment of the epidemiology of amebiasis: state of the art. Infect Genet Evol. 2009;9(6):1023-1032. doi:10.1016/j.meegid.2009.06.008

3. Raj L, Jacqueline AU. Clinical significance of the redefinition of the agent of amoebiasis. Rev Latinoam Microbiol. 2001;43(4):183-187.

4. Kloos H, Tesfayohanis TM. Intestinal parasites in Ethiopia. In: Kloos H, editor. The Ecology of Health and Disease in Ethiopia. Oxford: West view Press; 1993:223-225.

5. Erko B, Birrie H, Tedla S. Amebiasis in Ethiopia. Trop Geogr Med. 1995;47(1):30-32.

6. McConnel E, Armstrong JC. Intestinal parasitism in fifty communities on the central plateau of Ethiopia. Ethiop Med J. 2006;14:159-169.

7. Freeman CD, Klutman NE, Lamp KC. Metronidazole: a therapeutic review and update. Drugs. 1997;54:679-708. doi:10.2165/00003495199754050-00003

8. Powell SJ. New developments in the therapy of amoebiasis: progress report. Gut. 1970;11:967-969. doi:10.1136/gut.11.11.967

9. Samarawickrema NA, Brown DM, Upcroft JA, Thammapalerd N, Upcroft P. Involvement of superoxide dismutase and pyruvate ferredoxinoxidoreductase in mechanisms of metronidazole resistance in Entamoebahistolytica. J Antimicrob Chemother. 1997;40:833-840. doi:10.1093/jac/40.6.833

10. Drug administration and control authority of Ethiopia contents: standard treatment guideline for general hospitals, contents. 2010:45.
11. Qureshi H, Ali A, Baqai R, Ahmed W. Efficacy of a combined diloxanidefuroate-metronidazole preparation in the treatment of amoebiasis and giardiasis. J Int Med Res. 1997;25:167. doi:10.1177/ 030006059702500307

12. Nicole M, Mackey L, William AP. Clinical Evidence on Amoebic Dysentery. BMJ Publishing Group Ltd; 2011:918.

13. Walsh JA. Problems in recognition and diagnosis of amebiasis: estimation of the global magnitude of morbidity and mortality. Clin Infec Dis. 1986;8(2):228-238. doi:10.1093/clinids/8.2.228

14. Cost of living in Ethiopia: prices in Ethiopia. 2016. Available from: www.mumbeo.com/cost/countryresult. Accessed June 18, 2021.

15. Rompalo AM, Stamm WE. Anorectal and enteric infections in homosexual men. West J Med. 1985;142:647-652.

16. William AP, Upinder S. Diagnosis and management of Amoebiasis. Clin Infec Dis. 1999;29(6):1369.

17. Food, Ethiopian. Medicine and healthcare administration and control authority (EFMHACA). Model directive for inspection and licensing of medicines retail outlets (in Amharic). 2012.

18. Thoren K, Hakanson C, Bergstrom T, Johanisson G, Norkrans G. Treatment of asymptomatic amebiasis in homosexual men: clinical trials with metronidazole, tinidazole, and diloxanide. Sex Transm Dis. 1990;17(2):72-74. doi:10.1097/00007435-199004000-00005
ClinicoEconomics and Outcomes Research

\section{Publish your work in this journal}

ClinicoEconomics and Outcomes Research is an international, peerreviewed open-access journal focusing on Health Technology Assessment, Pharmacoeconomics and Outcomes Research in the areas of diagnosis, medical devices, and clinical, surgical and pharmacological intervention. The economic impact of health policy and health systems

\section{Dovepress}

organization also constitute important areas of coverage. The manuscript management system is completely online and includes a very quick and fair peer-review system, which is all easy to use. Visit $\mathrm{http}: / / \mathrm{www}$.dovepress.com/testimonials.php to read real quotes from published authors. 